\title{
The Construction of Exclusive Agricultural E-Commerce Platform of Hubei Province Focuses on the Development of "Agriculture, Rural and Farmers"
}

\author{
Quanhong Liu*1, Yufan $\mathrm{Li}^{1}$ and Xiang $\mathrm{Gao}^{2}$ \\ ${ }^{1}$ School of Business, Jianghan University, Wuhan, Hubei, 430056, China \\ ${ }^{2}$ Financial Investment Department, Wuhan Sports Center Development Co., Ltd., Wuhan, Hubei, 430056, China
}

\begin{abstract}
The production and marketing of agricultural products has always been bothering the government for a long time, and "' building an exclusive agricultural e-commerce platform in Hubei may be a good way to solve the unsalable problem of agricultural products and promote the sustainable development of "agriculture, rural and farmers". Thus, this paper discusses the necessity and advantages of building an exclusive agricultural e-commerce platform in Hubei Province, we found that the agriculture-related ecommerce has problems in the aspects of logistics, brand establishment and customer loyalty. Accordingly, this paper puts forward some countermeasures for the functional settings and operation strategies of the exclusive agricultural e-commerce platform in Hubei Province.
\end{abstract}

\section{Introduction}

To build a moderately prosperous society, the most prominent shortcoming lies in "agriculture, rural areas and farmers' problems". Because of this problem, the Party Central Committee has promoted a series of strategic deployments on "agriculture, rural areas and farmers' issues". This strategic deployment has enabled the steady improvement of eight shortcomings in rural areas, including public infrastructure, water supply, people's living environment, education, health care, social security, public culture, and ecological environment. The number of rural poor people continues to decline (Fig.1). However, the problems related to the production and marketing of agricultural products above the issues of agriculture, rural areas and farmers have been still troubling the governments at all levels. In particular, since the end of January 2020, the country has suffered from the strong impact of the new crown pneumonia epidemic, and Hubei Province, as the worst-hit areas, stopped the work and production. Inevitably, agricultural products breeding and marketing and other links inevitably suffered a heavy hit. The sudden arrival of the New Crown epidemic had a negative impact on farmers' sustainable income.

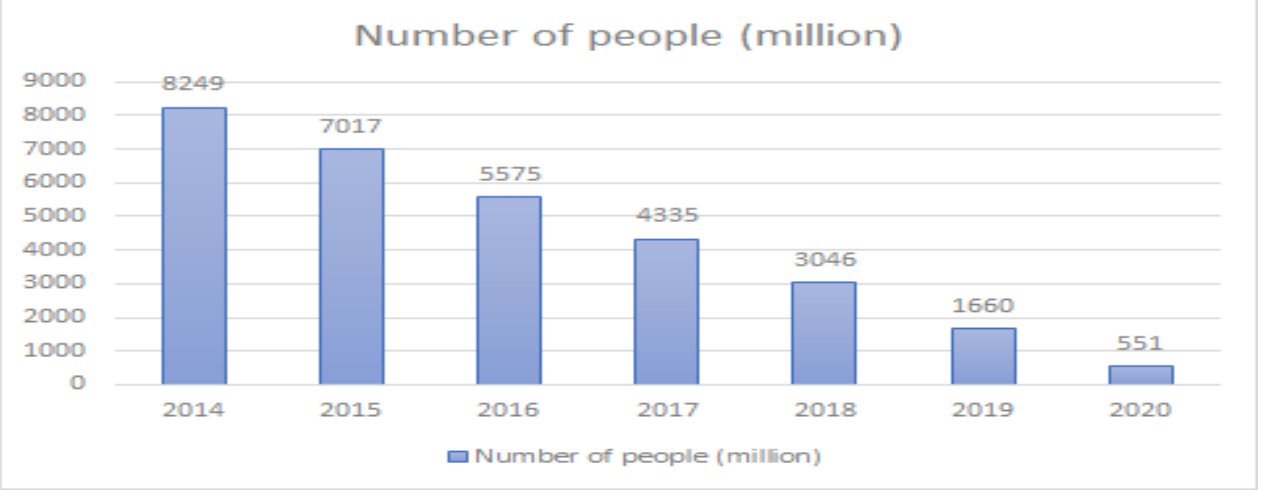

Figure 1. China's rural poverty population in the past 7 years

On the other hand, the epidemic control measures implemented around the world have objectively, however, promoted the prosperity and development of e-commerce platforms. Web celebrity and live-streaming with goods have entered the public eye as eye-catching buzzwords in
2020. Therefore, agriculture, rural areas, farmers will take advantage of the "Internet + agricultural products" sales model. Focusing on building an exclusive agricultural ecommerce platform in Hubei Province may solve the current sales dilemma of agricultural products. I hope that

*Corresponding author: qhliu@jhun.edu.cn 
the exclusive e-commerce platform for agriculture in Hubei Province can become a remedy to promote the sustainable development of the province's agricultural economy.

In order to make efforts to solve the " agriculture, rural and farmers " problems and promote the vigorous development of China's agricultural economy, this paper discusses the necessity and advantages of building an exclusive agricultural e-commerce platform in Hubei Province, and puts forward some countermeasures for the functional settings and operation strategies of the exclusive agricultural e-commerce platform in Hubei Province.

\section{The Necessity of Building an Exclusive Agricultural E-commerce Platform in Hubei Province}

The rise and development of the Internet, as well as the popularity of e-commerce platforms, smart phones, has partly changed people's life and consumption concept, closed the distance between the buyer and the seller through the network and platform. At present, the main agricultural e-commerce platforms are such as Tmall, Taobao, JD and micro-business. To a certain extent, these agricultural e-commerce platforms help alleviate the current situation of stagnant agricultural products and expand the scope of dissemination and transportation of agricultural products. However, there are many problems surrounding the operation of related products on the ecommerce platform, mainly as follows.

\subsection{The quality of products is difficult to guarantee}

The life cycle of agricultural products is relatively long and the profit margin is not high. But in the requirements for freshness and packaging, transportation, etc. are very strict. At present, the cold chain logistics corresponding to agricultural products is not perfect, the transportation of agricultural and products will lead to the loss of the quality of agricultural products received by consumers, which indirectly leads to the poor experience of customers on the quality of agricultural products purchased online. In order to avoid the loss of agricultural products as much as possible, when dealing with long-distance transportation, agricultural products are often picked early before they reach maturity. For example, cantaloupe is often picked at six maturity, but there is a huge gap between the sweetness and taste of six mature cantaloupe picked and stored until eight minutes ripe and the natural maturity of eight mature melons.

\subsection{Unstable operation of agricultural merchants}

At present, most farmers rely on previous years' experience in planting agricultural products, without professional and scientific guidance and training, so the harvest cannot be steadily guaranteed. At the same time, the production of many agricultural products is objectively seasonal, resulting in an uneven supply of products. This seasonal characteristic of agricultural products makes it difficult for the e-commerce company with a high degree of specialization to operate continuously regardless of the season. The business model of constantly changing product categories is not conducive to establishing a strong brand position in the minds of customers, which affects customer loyalty.

\subsection{Low profit space inhibits the enthusiasm of peasant households}

The high commission of the e-commerce platform squeezes the profit space of farmers, and restrains their enthusiasm to use the e-commerce platform to sell their products. The high degree of homogeneity of agricultural products is also not conducive to the formation of brand loyalty, and price wars are imminent, which further squeezes farmers' profit margins and inevitably frustrates farmers' enthusiasm to produce and sell agricultural products in e-commerce platforms.

\subsection{The degree of education hinders the use of farmers on the e-commerce platform}

Farmers work hard and income is unstable, so most of the educated are not willing to return to their hometowns to grow agricultural products, which indirectly leads to China's current farmers are generally not well educated. It is also due to the general lack of education of farmers, as well as the lack of understanding of the operation of the ecommerce platform, there is a certain degree of difficulty in the use of the operation of the e-commerce platform. Because of the asymmetry of information in the market, farmers are vulnerable to the infringement of bad merchants and even suffer from network fraud.

\subsection{The quality of agricultural products varies due to the difficulty of electricity regulation}

At present, it is difficult for the relevant departments to supervise the agricultural products sold on e-commerce platforms. The quality of agricultural products also does not have a better standard that can be measured. These reasons lead to the uneven quality of agricultural products on the e-commerce platform, such as substandard products pesticide residues, corruption and many other problems, which greatly affects consumers' trust and purchase enthusiasm for agricultural products on the e-commerce platform.

\subsection{Insufficient scale is difficult to form counterpart support}

Agricultural planting and breeding of small-scale, scattered distribution and other characteristics lead to the difficulty of forming scale. The basic feature of China's traditional agriculture is "self-employed" agriculture, mostly family-based production units, inheriting the Chinese tradition of meticulous farming. The selfemployed farmers choose their own planting projects, 
forming the sustainable development of a variety of agricultural operations. However, individual operation has resulted in low production level and poor production efficiency. Therefore, the government often has the intention to support counterparts, but nowhere to focus on.

\section{The Advantages of the Exclusive Agricultural E-commerce Platform}

"Whether the problem of "agriculture, rural areas and farmers" can be fundamentally solved is the key to winning the battle against poverty and building a well-off society. In order to better solve the above problems, we believe that the current situation of "agriculture, rural areas and farmers" in our province should be based on the characteristics of the province, to create our province's exclusive agricultural e-commerce platform, combining agriculture, agricultural products and agricultural tourism, integrating farmers, the government and consumers together. The relevant government departments will supervise the platform, so that the exclusive agricultural ecommerce platform will become the signboard of Hubei's agricultural, rural and farmers' products. The advantages of the agriculture-exclusive e-commerce platform mainly lie in.

\subsection{Solving transportation problems and guaranteeing product quality}

The main service targets of the platform are positioned within the province, and distribution routes are developed based on orders on the platform, and community-based distribution points are established to achieve uniform distribution at regular intervals. Such a transportation plan is conducive to shortening the spatial distance between buyers and sellers, and can greatly alleviate the difficulties of packaging and cold chain transportation. This can reduce transportation costs while safeguarding product quality and enhancing consumer satisfaction with ecommerce services.

\subsection{Optimizing industrial structure and forming aggregation effect}

Through the design of the section based on the characteristics of agricultural products planting and breeding in the province, farmers in the whole Hubei Province can be guided to adjust and optimize the product structure and form a regional scale effect.

\subsection{Increase profit level and mobilize farmers' enthusiasm}

Improve the profit level can be reduced by reducing the intermediate buying and selling links, reducing the fees of the platform or even can develop a free policy for specific agricultural products, etc., can effectively improve the level of profitability of farmers, which can improve the enthusiasm of production from the demand of farmers to a certain extent.

\subsection{Reduce transaction barriers and promote fair trade}

First of all, the most basic technical problems are solved, technical support is provided to farmers, and farmers are guided to make good use of the functions of the platform. Secondly, through the establishment of farmer information certification system, it can ensure the authenticity and reliability of the platform as well as the accurate positioning of agricultural products, which is conducive to the discussion of price according to quality and the reduction of information asymmetry to ensure fair trade.

\subsection{Government regulation endorsement, enhance consumer trust}

The e-commerce platform with government regulation endorsement is more likely to be trusted by farmers and consumers, which is conducive to pulling consumers scattered in other e-commerce platforms back to the province for consumption, as well as the use of the platform by foreign workers in Hubei to promote local economic development.

\subsection{Facilitate counterpart support and showcase the achievements of benefiting farmers}

Based on the province's exclusive agricultural ecommerce platform is conducive to the relevance and direction of the implementation of the province's agricultural policies. The platform can also indirectly become a showcase for the government's achievements in the construction of "agriculture, rural areas and farmers", so that the public can clearly understand the policy orientation and phased achievements of our province in solving the problems of "agriculture, rural areas and farmers" and strive for positive responses from the public.

\section{The Function Setting of the Exclusive Agricultural E-commerce Platform of Hubei Province}

Combined with the characteristics of agricultural products and the operation rules of the e-commerce platform, the following five sections can be set up in the province's exclusive agricultural e-commerce platform (Fig. 2): 


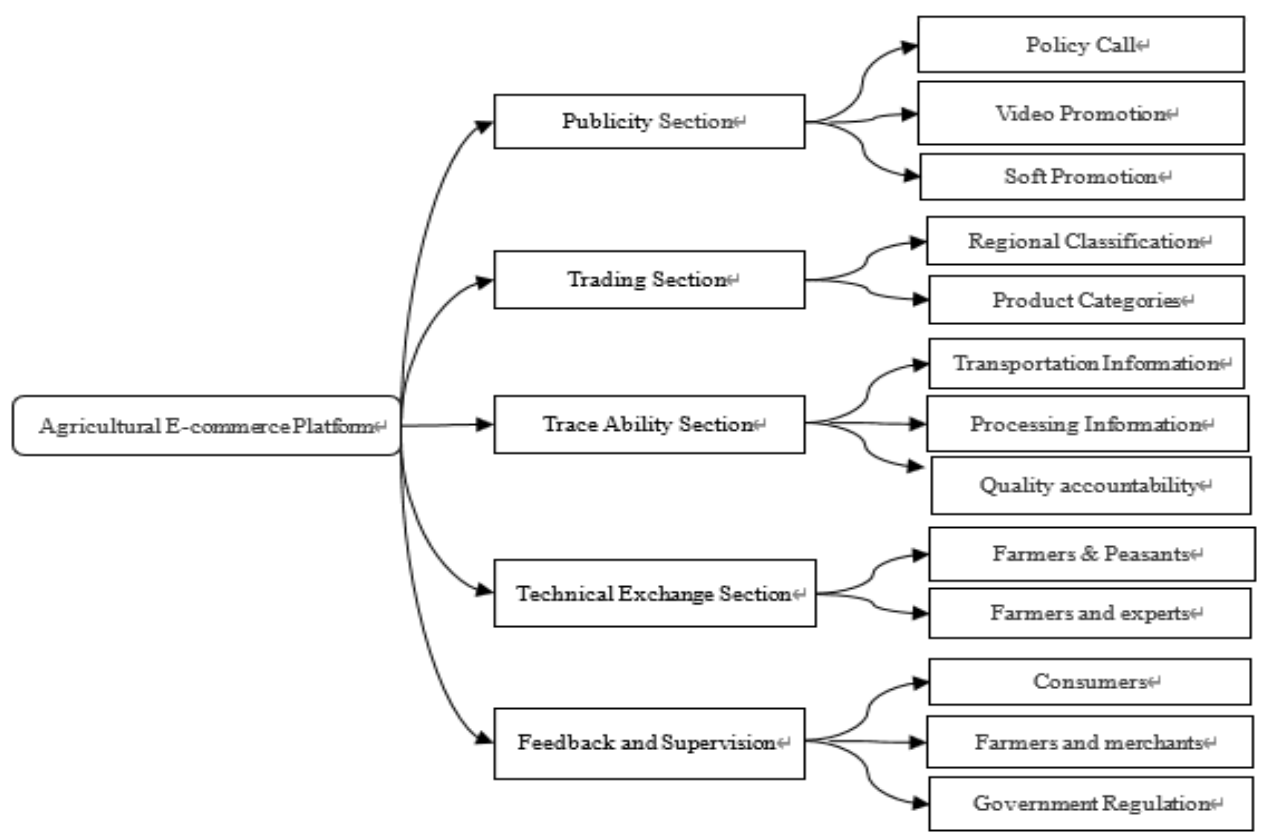

Figure 2. The Function Setting of the Exclusive Agricultural E-commerce Platform

\subsection{Agricultural products publicity section}

The functions of this section mainly include: (1) policy propaganda. The e-commerce platform as the government's agricultural policy and various laws and regulations of the propaganda position, so that farmers and consumers can better and more directly understand the national "agriculture, rural areas, farmers issues" policy guidelines; (2) short video promotion. Farmers can promote the characteristics of crops to consumers and teach them unique local cooking methods. Consumers can upload a buyer's show to share their shopping experience and feelings. Links to the corresponding agricultural products can be embedded under each video to facilitate consumers' purchase; (3) soft copy promotion. Embedding the regional culture into the product promotion, publishing the tourism resources and brief introduction of agricultural specialties from different places to attract consumers' attention and consumption.

\subsection{Agricultural products trading section}

The interface design of this section needs to be clear and concise, so that consumers can quickly find the agricultural products they need. The classification of agricultural products can be combined in two ways: one is by region to create regional agricultural specialties and unified brand image. Firstly, by mainly promoting one agricultural product, and then carry out brand extension strategy after the brand image is established. Encourage regional joint sales, and also integrate agricultural specialties with local tourism resources. For example, picking a fruit, pushing the local orchard picking project to consumers with the same interface, and pushing the preferential activities in real time, which can not only enhance consumers' experience, but also promote the promotion of tourism resources; secondly, classify by agricultural products category. This classification is mainly for consumers with relatively clear shopping purposes, which helps them reach their targets directly and improve shopping efficiency. Agricultural products can further adopt a grading system, setting different price zones according to the superiority and inferiority levels to meet the needs of consumer groups with different purchasing abilities. Through the design of the section, it is convenient for consumers to meet their own needs and thus increase their loyalty to the platform.

\subsection{Agricultural products traceability section}

Each sold agricultural product has its own QR code printed on the package or even the transportation package. Consumers can scan and open the link to get information about the production, processing environment and processing process of agricultural products in this section, so as to make the production and transportation of agricultural products transparent. And the QR code is embedded with information about local tourism resources. Such an action can enhance consumers' trust in the platform and products, and also facilitate their understanding of the local customs and customs of the products, and facilitate the pursuit of responsibility for orders with problems.

\subsection{Technical exchange section}

The main function of this section is to provide remote professional guidance on agricultural planting, breeding, tourism project development, etc. The technical exchange section in the platform promotes information exchange and sharing among farmers. Relevant government departments can invite relevant agricultural experts to the platform, share small videos related to agricultural technology, hold online agricultural knowledge lectures from time to time, and give answers to technical help information released by farmers on the platform. Farmers 
can use the technical videos of experts to improve their own farming techniques and seek help in time when they encounter problems.

\subsection{Feedback and supervision section}

The platform provides online transaction support and backup transaction information as the basis for resolving transaction disputes. Any feedback from consumers and farmers will be given within 24 hours, and clear solutions to simple problems will be given in time. For difficult problems, provide the problem handling process and counterpart management department, clarify the problem handling period and follow-up action guidelines, and improve the efficiency of dispute handling. A platform suggestion column is set up to provide rewards for good suggestions, to pool the wisdom and promote the benign development of the platform.

\section{The Operation Strategies the Exclusive Agricultural E-commerce Platform Hubei Province}

\subsection{Do a good job of promoting the platform}

In order to pull consumers scattered in other e-commerce platforms back to the province, the first thing we must do is to promote the work. First, we should play the warm card, promote the spirit of "care for the hometown", "revitalization of Hubei", "the rise of central", etc., to guide consumers to the platform to consume; second, encourage enterprises and institutions in the province in Second, encourage enterprises and institutions in the province to give out employee benefits with agricultural specialties as the main products, and guide them to publish bidding information on the platform, and encourage farmers to form regional product alliances and actively respond to bids; Third, make full use of the provincial publicity resources to promote the platform, such as publicity in newspapers and magazines, authoritative public numbers or video websites, and joint mobile, Unicom and telecommunications operators to promote SMS, etc.

\subsection{Promote agricultural transformation and upgrading}

The transformation and upgrading of agricultural products are first of all quality upgrading, and the traditional farming model usually means low efficiency and rough quality. Therefore, farmers should be guided to change their mindset, keep pace with the development of the times and actively adopt modern farming techniques and processing modes. The grading and pricing mechanism of agricultural products should be strictly enforced to eliminate the crisis of consumer trust that may result from mixing and selling good and bad products. The grading management of agricultural products can also further guide farmers to adjust their product structure through the mechanism of elimination of winners and losers, optimize the layout of agriculture in the province, and turn agricultural production increase into agricultural quality production. The transformation and upgrading of agricultural products should also be reflected in the upgrading of packaging, to avoid the embarrassing situation of "first-class products, second-rate packaging, third-rate prices". Therefore, agricultural products should pay attention to the quality of packaging design, to be able to protect the product, but also in the minds of consumers to form the impression of high quality. Regional cultural elements can be incorporated into the packaging, but pompous, tangible but not real should be eliminated.

\subsection{Do a good job in technical poverty alleviation}

In view of the generally low level of education of farmers, the platform should actively do a good job of technical poverty alleviation work. First, establish e-commerce consulting departments at all levels in villages, towns, counties and cities to provide low-cost or even free consulting services to assist farmers to make full use of the e-commerce platform; second, provide farmers with technical support in planting and breeding through the introduction of agricultural technology talents, supplemented by online technical guidance from agricultural experts. Third, the introduction of artificial intelligence, such as the sowing of agricultural products, is harvesting, etc. The introduction of artificial intelligence part of the simple labour part of the use of machinery instead of manual labour, reducing the labour costs of labour.

\subsection{Standardize management logistics}

After the platform can run stably, we should continue to strengthen the supervision and improvement of logistics. Establish a database of agricultural products demand, set up collective freshness warehouses in Hubei province by city, and store three to five days of agricultural products in advance according to the database for each city's agricultural products preference. And then establish agricultural products dispatching points as a community unit, which can realize the fixed time dispatching of agricultural products and reduce transportation cost and human resources consumption by collective dispatching. For agricultural products delivery and transportation, two options can be implemented: First, expedited orders can be delivered in time. For those who have such needs, a certain logistics expediting fee can be charged on the basis of collective delivery. Through the community fixed-point collective delivery to reduce the logistics and transportation costs, the same day purchase the next day delivery to give enough time for logistics preparation can also meet the daily needs of consumers of agricultural products.

\section{Conclusion}

In this paper, through the analysis of the status of agriculture-related e-commerce, we found that the agriculture-related e-commerce has problems of the 
"agriculture, rural and farmers" in the aspects of logistics, brand establishment and customer loyalty, etc, which is an urgent problem to be solved. In this regard, we propose the establishment of a special three agricultural e-commerce platform, not only to solve the problem of agricultural sales, but also a platform to help farmers solve agricultural technology problems; a professional three agricultural ecommerce platform help to establish regional agricultural brand and enhance customer loyalty, which may make efforts to solve the " agriculture, rural and farmers " problems and promote the vigorous development of China's agricultural economy.

\section{References}

1. Li, L. (2020) Another way to open rural revitalization from Li Ziqi's IP operation. Communication, 18:161162.

2. Kuang, M. (2020) Service "three rural" postal logistics operation mode analysis. Modern Agriculture Research, $10: 110-111$.

3. Zhao, N. (2019) Research on the problems and countermeasures of precise poverty alleviation of agricultural products in Hubei Province through ecommerce. Mall Modernization, 18 :31-32.

4. Song, F. (2020) Exploring the training mode of three agricultural e-commerce talents based on rural revitalization. Modern Rural Technology, 01:19-20.

5. Zhang, X. (2021) The construction of an e-commerce platform for agricultural products in poor areas. China Fruit Tree, 04:118.

6. Fang, M. (2021) Cross-border e-commerce logistics model strategy analysis. China's collective economy, 10:104-105. 